\title{
Corrigendum: The Research Progress of Direct KRAS G12C Mutation Inhibitors
}

\author{
Ai Yang, Min Li* and Mingzhi Fang \\ Department of Oncology, Nanjing Hospital of Chinese Medicine Affiliated to Nanjing University of Chinese Medicine, Nanjing, \\ China
}

Keywords: KRAS mutation, targeted drugs, oncogene, inhibitor, oncology

\section{A Corrigendum on}

The Research Progress of Direct KRAS G12C Mutation Inhibitors

by Yang, A., Li, M., and Fang, M. (2021). Pathol. Oncol. Res. 27:631095. doi: 10.3389/pore.2021. 631095

In the original article, there were mistakes in the legend for all of the figures as published. The source of the pictures cited in the article were not included. The correct legends appear below.

The sources for the figures have been added to the reference list, and the reference numbering has been updated to accommodate this. The new references are appear below.

The authors apologize for this error and state that authorization has been obtained from the author of each picture, and this does not change the scientific conclusions of the article in any way. The original article has been updated.

\section{OPEN ACCESS}

Edited and reviewed by: József Timar. Semmelweis University, Hungary

*Correspondence:

$\mathrm{Min} \mathrm{Li}$

doctorlimin@163.com

Received: 09 December 2021 Accepted: 29 December 2021 Published: 24 February 2022

Citation:

Yang A, Li M and Fang M (2022) Corrigendum: The Research Progress of Direct KRAS G12C Mutation Inhibitors. Pathol. Oncol. Res. 27:1610250. doi: 10.3389/pore.2021.1610250

\section{REFERENCES}

3. Prior IA, Lewis PD, and Mattos C. A Comprehensive Survey of Ras Mutations in Cancer. Cancer Res (2012) 72(10):2457-67. doi:10.1158/0008-5472.can-11-2612

4. Simanshu DK, Nissley DV, and Mccormick F. RAS Proteins and Their Regulators in Human Disease. Cell (2017) 170(1):17.

14. Huili L, Fei J, Jiwei R, Tao L, Yadong C. Research Advances on KRAS and Its Inhibitors. Acta Pharmaceutica Sinica (2020) 44(1):43-55

20. Xin L, Yijun W, and Pingyu L. Recent Advancement In Targeting The KRASG12C Mutant For Cancer Therapy. Acta Pharmaceutica Sinica (2021) 56(2):374-82.

30. Fell JB, Fischer JP, Baer BR, Blake JF, Bouhana K, Briere DM, et al. Identification of the Clinical Development Candidate MRTX849, a Covalent KRASG12C Inhibitor for the Treatment of Cancer. J Med Chem (2020) 63(13):6679-93. doi:10.1021/ acs.jmedchem.9b02052

33. Tran TH, Alexander P, Dharmaiah S, Agamasu C, and Balius TE. The Small Molecule BI-2852 Induces A Nonfunctional Dimer Of KRAS Proc National Academy Sci. (2020) 117(7).

Copyright () 2022 Yang, Li and Fang. This is an open-access article distributed under the terms of the Creative Commons Attribution License (CC BY). The use, distribution or reproduction in other forums is permitted, provided the original author(s) and the copyright owner(s) are credited and that the original publication in this journal is cited, in accordance with accepted academic practice. No use, distribution or reproduction is permitted which does not comply with these terms. 


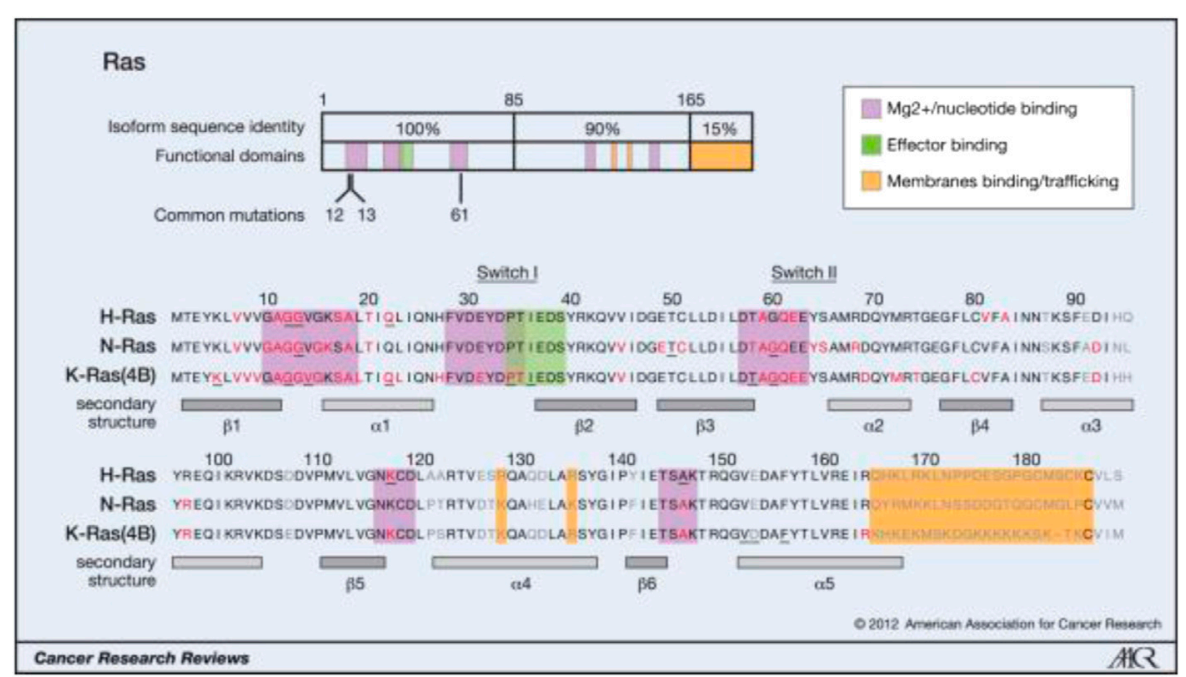

FIGURE 1 | Oncogenic mutations of Ras isoforms. (Reprinted by permission from Cancer Research [3]).

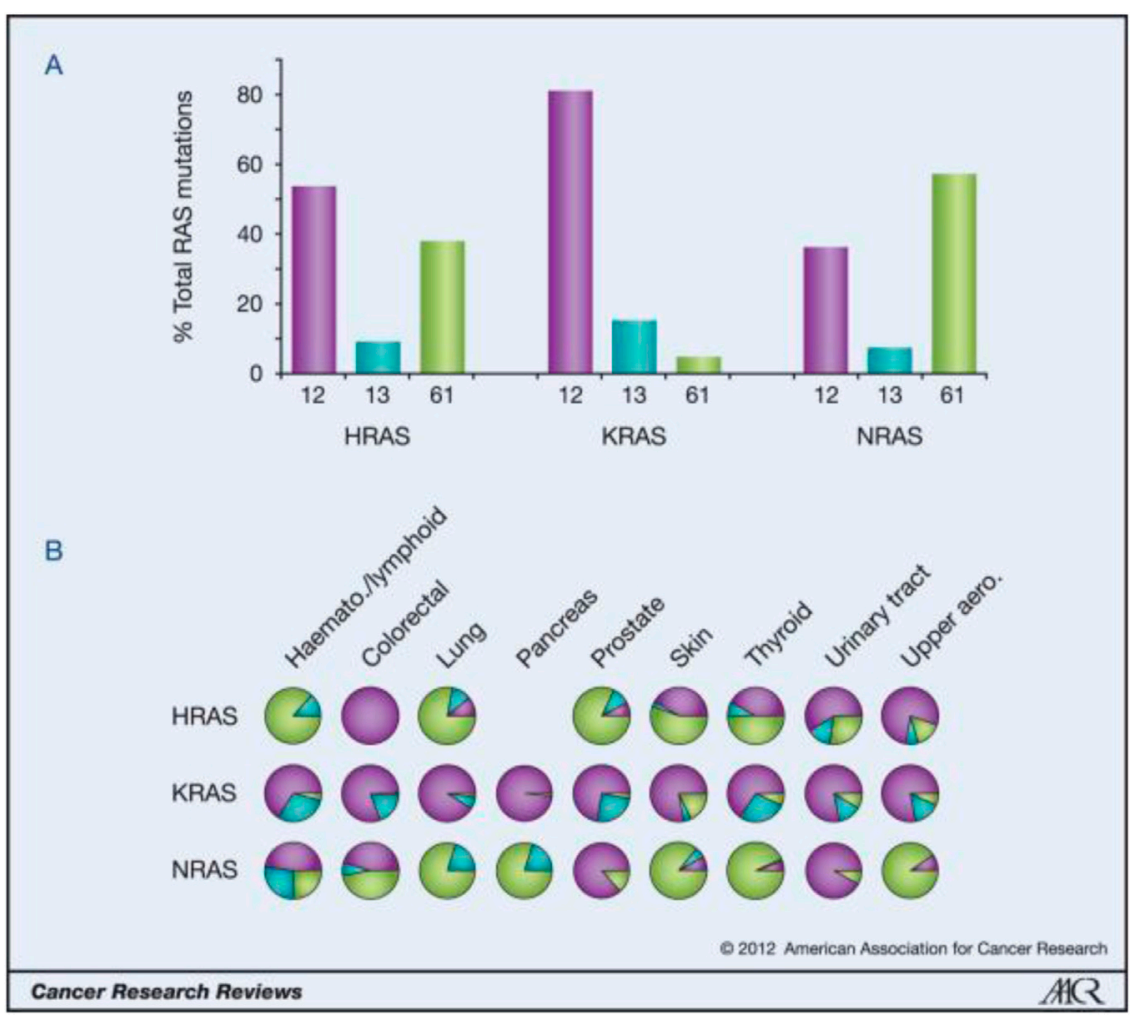

FIGURE 2 | Ras isoform-specific codon mutation bias. (Reprinted by permission from Cancer Research [3]). 


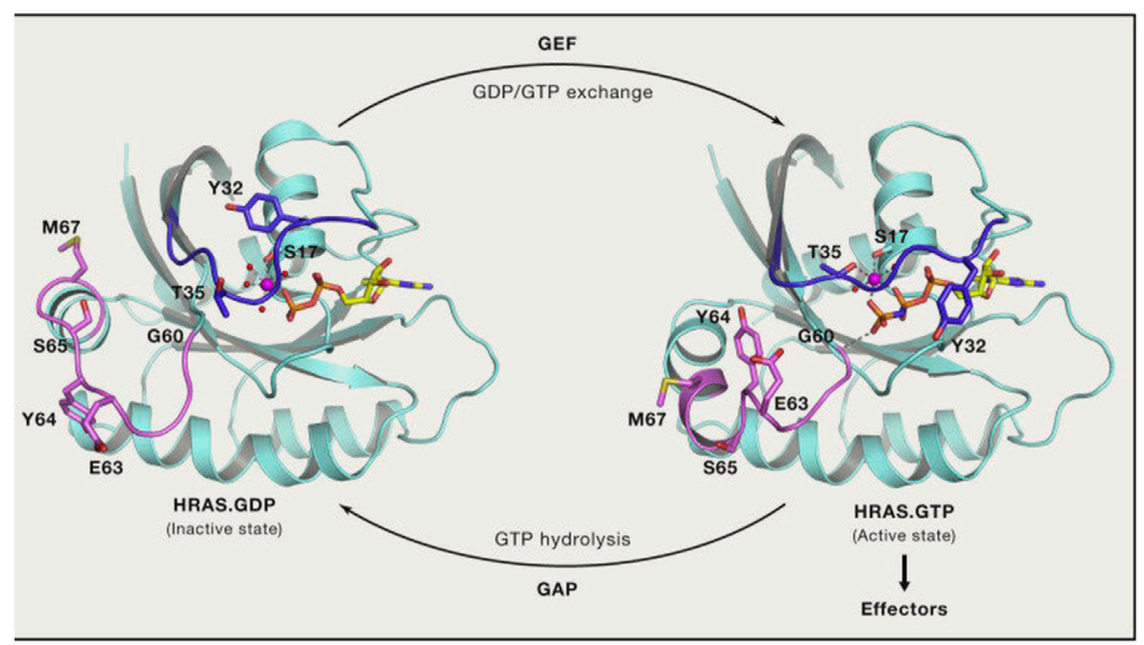

FIGURE 3 | RAS GTP/GDP change. (Reprinted by permission from Cell [4]).
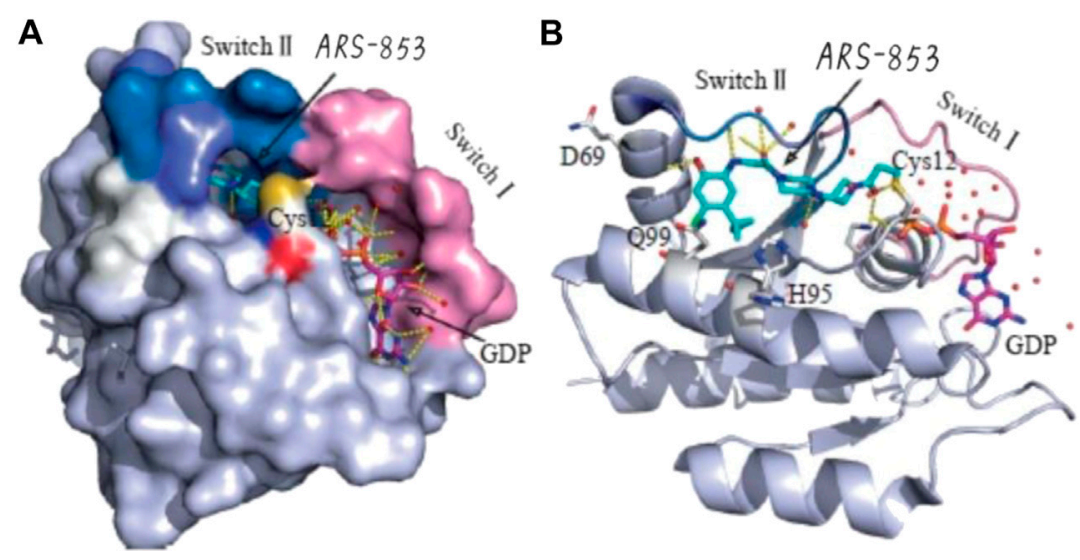

X-ray co-crystal structure of ARS-853 and KRAS G12C

FIGURE 4 | The acrylamide of ARS-853 can form covalent bond with 12 cysteine and extend to switch II region, aromatic nucleus occupies hydrophobic region, the cyclopropyl group and the surrounding amino acids form a strong van der Waals force. (Reprinted by permission from Progrss in Pharmaceutical Sciences [14]). 


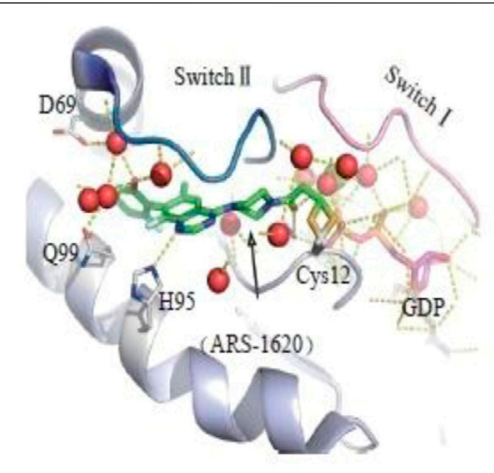

X-ray co-crystal structure of ARS-1620, compound 14 and KRAS G12C

FIGURE 5 |X-ray co-crystal structure of ARS-1620, compound 14 and KRAS G12C. (Reprinted by permission from Progrss in Pharmaceutical Sciences [14]).

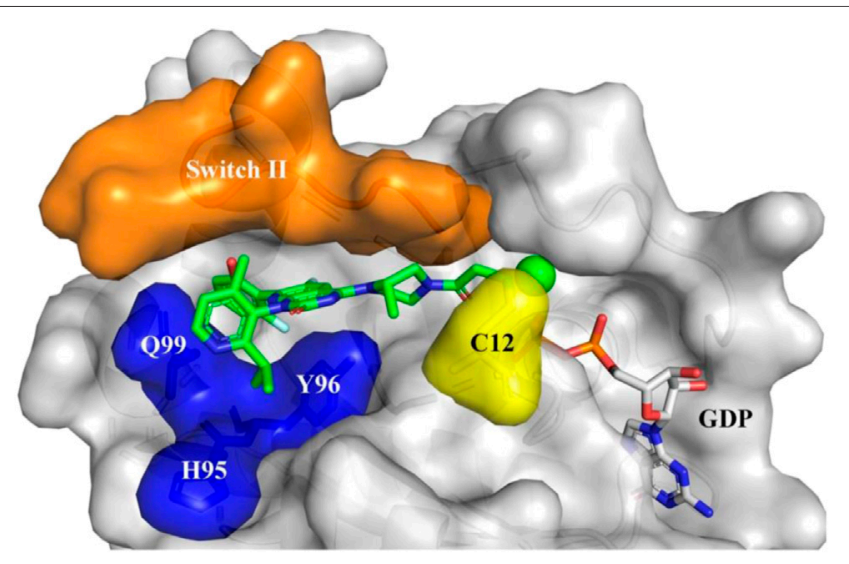

FIGURE 6 | Sotorasib (AMG510) binding to KRAS-G12C protein. Orange: Switch II domain; Yellow: C12 residual; Blue: A cryptic pocket composed of H95, Y96, and Q99. AMG510 (green) and GDP (gray) are shown in sticks. (Reprinted by permission from Acta Pharmaceutica Sinica [20]). 


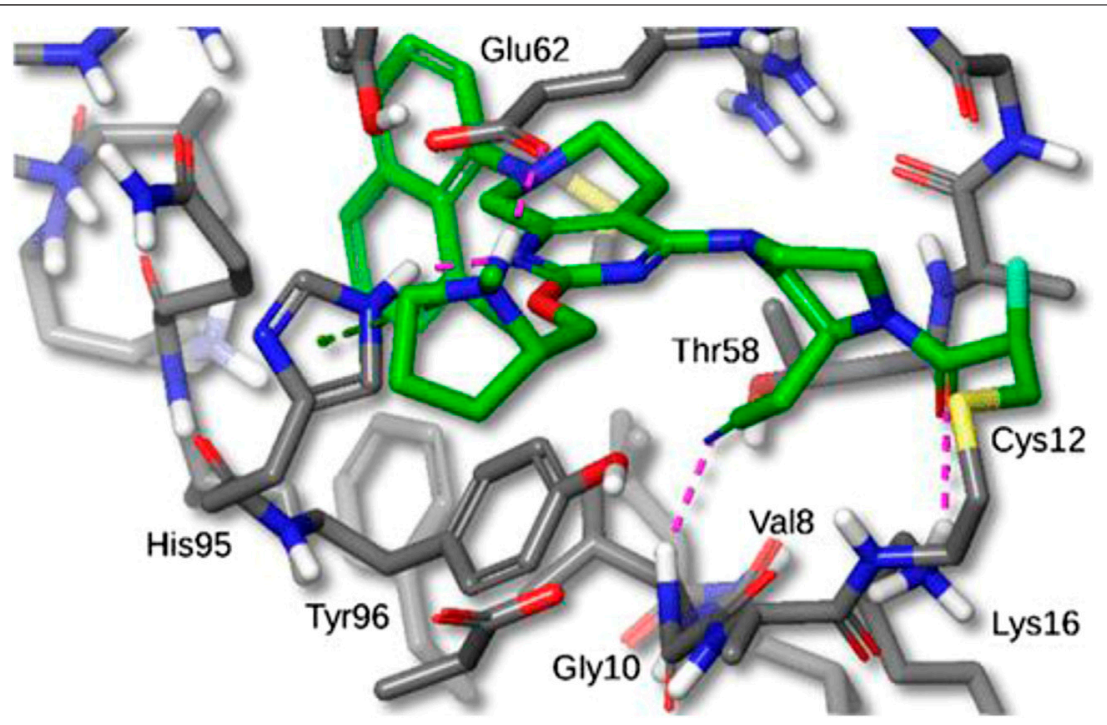

FIGURE 7 |X-ray crystal structure of MRTX849 bound to KRASG12C with $1.94 \AA$ resolution, hydrogens added for clarity. (Reprinted by permission from [30], further permissions related to the material excerpted should be directed to the ACS).

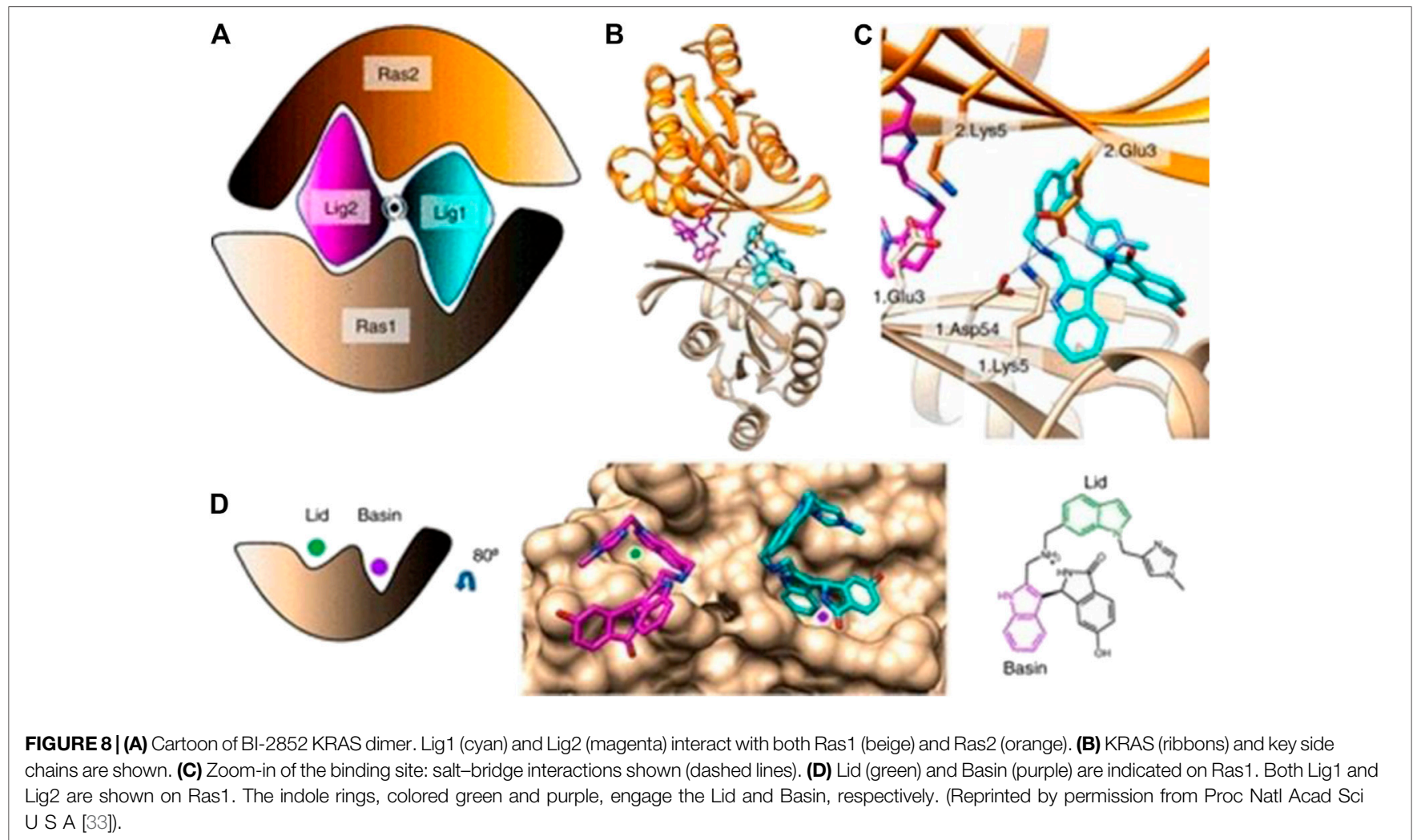

